Lepr Rev (1995) 66, 229-234.

\title{
Tibialis posterior transfer in the correction of footdrop due to leprosy
}

\author{
D. SOARES \\ Anandaban Leprosy Hospital, The Leprosy Mission, PO Box 151, \\ Kathmandu, Nepal
}

Accepted for publication 27 March 1995

\begin{abstract}
Summary In the correction of footdrop due to leprosy neuritis the tibialis posterior muscle is re-routed and used to provide dorsiflexion of the foot. This study of tibialis posterior transfer was carried out to compare the results of the circumtibial and interosseous routes. There is no significant difference in the range of motion between either route though the range of the interosseous route is more functional (better dorsiflexion). The interosseous route is preferable as this results in a significantly lower incidence of recurrent inversion deformity of the foot at long-term follow-up when compared with the circumtibial route.
\end{abstract}

\section{Introduction}

Footdrop due to the paralysis of the anterior tibial and peroneal muscles is found in 2$5 \%{ }^{10,16}$ of newly diagnosed leprosy patients as a result of leprosy neuritis.

Leprosy neuritis affects nerves where they are close to the skin and pass through a narrow fibro-osseous canal. In the lower limb this involves the lateral popliteal nerve around the neck of the fibula (leading to footdrop) and the posterior tibial nerve at the tarsal tunnel (leading to anaesthesia of the plantar surface). When both these nerves are damaged then the main impact during walking falls on the anaesthetic forefoot rather than the heel, with plantar trophic ulceration being the almost inevitable result. This study assesses the outcome of tibialis posterior transfer (TPT) in the correction of footdrop due to leprosy and specifically compares the circumtibial (CT) with the interosseous $(\mathrm{IO})$ route.

\section{Methods}

One hundred and ten footdrop corrections in 95 patients ( 83 male and 12 female) on a total of 105 feet were followed-up. These were performed in the years 1987-93. Ten patients had bilateral corrections. Nine operations were redone when the earlier operation had failed, i.e. the patient developed recurrent inversion or footdrop 
persisted. For all patients, data was collected prospectively (pre-operative, immediately out of Plaster of Paris (POP) and discharge 'angles'). Final follow-up data (at least 6 months post-op) on recurrent inversion was available in 69 patients. This was carried out during 1994. In $59(53.6 \%)$ of these patients 'angles' (measurement of active dorsiflexion (ADF) and active plantarflexion (APF)) and further data on recurrent ulceration and bone loss are also available.

Angle measurements for the foot were taken with neutral as $90^{\circ}$ and $20^{\circ}$ dorsiflexion as $70^{\circ}$. Inversion of more than $5^{\circ}$ was considered as significant. Range of motion (ROM) was measured as active APF-active ADF.

Abbreviations used for some muscles include: tibialis anterior (TAN), extensor hallucis longus (EHL), extensor digitorum longus (EDL), peroneus brevis (PB), peroneus tertius (PT), tibialis posterior (TP).

\section{Technique}

The main details of technique for the IO route have been described elsewhere, however some important points need to be made. I routinely lengthen the tendo achilles by an open $\mathrm{Z}$ lengthening so as to enable easy passive dorsiflexion to at least $65^{\circ}$. It is important that the IO membrane is widely opened and that the TP is rerouted from the posterior compartment to the anterior compartment lateral to the wasted belly of TAN in order to prevent adhesions to the tibia and to get better lateral lift. The lateral slip is attached to the PB or PT tendons at maximum tension. The medial slip is sutured to the TAN tendon at neutral tension. The leg is placed in a POP cast for 3 weeks with the foot dorsiflexed to $65^{\circ}$ to relieve tension on the joins. In the CT route the TP tendon is brought medially around to the front of the tibia subcutaneously. After being withdrawn into the lower medial leg the TP tendon is split into two slips and tunnelled to the dorsum of the foot. The slip to the peroneal tendons must cross the ankle joint at least $3 \mathrm{~cm}$ above the mid-ankle to ensure eversion.

After 3 weeks the cast is split and intensive reeducation is begun. This includes contracting only TP to dorsiflex the foot and later practicing co-ordination exercises (alternate dorsiflexion and relaxation but not plantar flexion) and relearning 'swing phase walking' with crutches. In the third week the patient is allowed partial weight bearing in parallel bars or with crutches and continues to practice swing phase walking in parallel bars. From the fourth week out of POP (at least 6 weeks post-op) plantar flexion is encouraged and the patient is given a sandbag $(500-1000 \mathrm{gm})$ to use during exercising to encourage strengthening of the muscle. They also gradually increase weight bearing so that by the sixth week out of POP they can walk without crutches. In the sixth week out of POP they practice on stairs and usually at the end of that week are ready for discharge.

\section{Results}

The average age was 33.5 years (13-75 years). Fifty-two operations were on the left foot $(47 \%)$ and 58 on the right foot $(53 \%)$. The average duration of footdrop prior to operation was 4 years 5 months. Eighty feet $(73 \%)$ had a complete footdrop while in 30 
feet $(27 \%)$ only the dorsiflexors were affected and the evertors were normal. The CT route was used in 43 feet $(39 \%)$ mostly before 1992. The IO route was used in 67 feet $(61 \%)$.

The medial slip of the TPT was attached to TAN in 104 feet $(95 \%)$ and to EHL (an old preferred method) in 6 feet (5\%). The lateral slip was attached to EDL in 56 feet $(51 \%)$ and to the peronei in 54 feet $(49 \%)$. It is my impression that the attachment to EDL leads to a higher incidence of claw toes in mobile toes and so is not now used.

The average duration of immobilization in POP was 28 days (21-42 days) and the average time to discharge from the date of operation was 10 weeks (6-30 weeks). The average final follow-up was 31 months (6-85 months). Of the 59 feet for whom pre-op and final follow-up data on further bone loss (ditigal or metatarsal absorption - a measure of recurrent ulceration) is available, $45(76 \%)$ did not have any further bone loss and only 2 feet $(4 \%)$ suffered more than 2 'points' bone loss after the operation. (Each toe and each metatarsal head counts as one 'point'.)

All of the CT TPTs and half of the IO TPTs were done prior to 1992. Since 1992 we have performed IO TPT almost exclusively ( 2 exceptions-patients with a calcified unyielding IO membrane). Thus there is a significant difference in the duration of followup $(\mathrm{CT}=4.27$ years, $\mathrm{IO}=1.55$ years $)$ between $\mathrm{CT}$ and $\mathrm{IO}$ TPTs.

Long-term follow-up data regarding inversion was available in 69 patients. Of 26 patients who had CT TPTs 21 had recurrent inversion compared with only $1 / 43$ of those who had an IO TPT. (Even this one patient had an unusual variation of the operation performed by another surgeon with the whole TP tendon attached medially and a fascia lata graft connecting the peroneus to the TP tendon at the anterior lower leg. In this case, apparently, the fascia was not attached with enough eversion and may have stretched.)

The relative risk for inversion at final follow-up for the CT route compared with the IO route is 8.97 with an odds ratio of 176.4 ( $\chi$-square $45.91, p=0.0000000)$. Having only an anterior muscle paralysis (normal evertors) was not protective against inversion at final follow-up in CT TPT. Of 16 patients with medial footdrop $3 / 6$ who underwent CT TPT developed recurrent inversion $v s 0 / 10$ in the IO TPT group $(p=0.036)$. For differences in angles between $\mathrm{CT}$ and $\mathrm{IO}$ routes see Table 1.

Only 6 patients in this study did not have a TAL. At final follow-up patients who had a TAL had a significantly greater likelihood of an ADF above $90^{\circ}$. Failure to do a TAL can lead to a poor result.

Table 1.

\begin{tabular}{lccc}
\hline & Circumtibial & Interosseous & $p$ value \\
\hline No. of feet operated & 34 & 67 & - \\
Long term follow-up & 26 & 43 & - \\
Recurrent inversion & 21 & 1 & $0 \cdot 00001$ \\
ADF at discharge & $81 \cdot 9^{\circ}$ & $77 \cdot 3^{\circ}$ & $0 \cdot 00003$ \\
APF at discharge & $102 \cdot 6^{\circ}$ & $89 \cdot 5^{\circ}$ & $0 \cdot 0264$ \\
ADF final follow-up & $90 \cdot 3^{\circ}$ & $81 \cdot 6^{\circ}$ & $0 \cdot 00009$ \\
APF final follow-up & $111 \cdot 6^{\circ}$ & $98 \cdot 8^{\circ}$ & 0.003 \\
ROM final follow-up & $21 \cdot 3^{\circ}$ & $18 \cdot 3^{\circ}$ & $0 \cdot 374^{*}$ \\
Final follow-up years & $4 \cdot 27$ & $1 \cdot 55$ & \\
\hline
\end{tabular}

* Not statistically significant. 


\section{Discussion}

In this study TPT (either route) provides ADF above $90^{\circ}$ in $80 \%$ of patients, with restoration of normal gait (ADF above $95^{\circ}$ ) in $94 \%$ of patients. A summary of some of the literature is given in Table 2 . ADF above $90^{\circ}$ is possible in between 65 and $95 \%$ of patients according to these studies. Richard ${ }^{9}$ has pointed out that for the transfer to function well, it should partly function as a tenodesis. That the transfer also has an active component is obvious from the $22^{\circ} \mathrm{ROM}$ of patients in this study. However it is important that this ROM should be in the functional range $\left(80^{\circ}-100^{\circ}\right)$ for normal gait. Depending on the terrain a patient with ADF (only up to $90^{\circ}$ ) may still have a normal gait if they live on the plains. Patients who live in the hills require a greater ROM $\left(10^{\circ} \mathrm{ADF}\right.$ and $10^{\circ} \mathrm{APF}$ ) in order to clear the ground going uphill and easily walk downhill.

The CT route however is associated with an unacceptably high rate of recurrent inversion leading to recurrent lateral border foot ulceration. This observation was made

Table 2. Comparison of published results of TPT

\begin{tabular}{|c|c|c|c|}
\hline & Route & Attachment & Result \\
\hline \multicolumn{4}{|c|}{ Author (number of feet) } \\
\hline Andersen $^{1}(108)$ & $\mathrm{CT} / \mathrm{IO}$ & $\begin{array}{l}\text { tarsal bone } \\
\text { or TA/EHL }\end{array}$ & $\begin{array}{l}\text { heel-toe gait in } 65 \\
\text { excellent or good in } 72\end{array}$ \\
\hline Andersen $^{2}(12)$ & $\mathrm{CT}$ & EHL/EDL & excellent/good in 11 \\
\hline $\begin{array}{l}\text { Carayon }^{3}(23) \\
(\mathrm{TPT}+\mathrm{FDL})\end{array}$ & IO & $\begin{array}{l}\text { TP-TA } \\
\text { FDL-EDL }\end{array}$ & $\begin{array}{l}\text { excellent ( }>50 \mathrm{ADF}) \\
\text { in } 18\end{array}$ \\
\hline Fritschi $^{4}$ & $\mathrm{CT} / \mathrm{IO}$ & tarsal bone & CT better ROM than IO \\
\hline Gunn $^{5}(56)$ & $\mathrm{CT} / \mathrm{IO}$ & tarsal bone & $\begin{array}{l}49 \text { satisfactory } \\
\text { criteria not stated }\end{array}$ \\
\hline \multirow[t]{3}{*}{ Hall $^{6}(65)$} & IO & EHL/cuneiform & 3 good, 1 poor ( 4 total) \\
\hline & $\mathrm{CT}$ & EHL/EDL (35) & $\begin{array}{l}10 \text { good, } 16 \text { fair } \\
6 / 23 \text { recurrent inversion }\end{array}$ \\
\hline & $\mathrm{CT} / \mathrm{IO}$ & $\begin{array}{l}\text { TP-TA (26) } \\
\text { FDL-EDL }\end{array}$ & 7 good, 11 fair \\
\hline \multirow[t]{2}{*}{ Malaivya $^{7}(98)$} & $\mathrm{CT}$ & cuneif orm (20) & 15 good heel-toe gait \\
\hline & & EHL/EDL (78) & 53 good heel-toe gait \\
\hline Palani $^{8}(76)$ & $\mathrm{CT} / \mathrm{IO}$ & & $62 \mathrm{ADF}$ above $90^{\circ}$ \\
\hline Richard $^{9}$ (39) & IO & EHL/EDL, PL & 37 ADF above $90^{\circ}$ \\
\hline Selvapandian ${ }^{11}$ (39) & $\mathrm{CT} / \mathrm{IO}$ & tarsal bone & CT better ROM than IO \\
\hline Srinivasan $^{12}(39)$ & $\mathrm{CT}$ & EHL/EDL, PT & $\begin{array}{l}22 \mathrm{ADF} \text { above } 90^{\circ} \\
12 \mathrm{ADF} \text { up to } 90^{\circ}\end{array}$ \\
\hline Thangaraj ${ }^{13}(68)$ & $\mathrm{CT}$ & TA/EDL & $\begin{array}{l}60 \text { patients }>25^{\circ} \text { ROM } \\
5 \text { patients recurrent inversion }\end{array}$ \\
\hline Warren ${ }^{14}(13)$ & IO & $\begin{array}{l}\text { TA/PB } \\
\text { 5th MT }\end{array}$ & 9 had good gait \\
\hline Weber $^{15}(25)$ & $\mathrm{CT} / \mathrm{IO}$ & $\mathrm{TA} / \mathrm{PB}$ & $21 \mathrm{ADF}$ above $90^{\circ}$ \\
\hline \multirow[t]{2}{*}{ Soares (110) } & CT (43) & TA/EDL & $38 \mathrm{ADF}$ above $90^{\circ}$ \\
\hline & IO (67) & $\mathrm{TA} / \mathrm{PB}$ & $65 \mathrm{ADF}$ above $90^{\circ}$ \\
\hline
\end{tabular}


by Hall $^{6}$ and Thangaraj ${ }^{13}$ in smaller groups of patients. CT TPT should be reserved for those patients with a calcified and unyielding IO membrane (usually elderly with recurrent inflammation/infection in the foot). If CT TPT is performed, the tendon bifurcation must be at least $3 \mathrm{~cm}$ above the ankle so that the line of pull is as close to the vertical as possible. Wherever possible IO TPT should be used.

There is no evidence (from this study) of the crippling adhesions associated with the IO route mentioned by Anderson ${ }^{1}$ as there is no signficant difference in active ROM at final follow-up (CT $14 / 16$ more than $10^{\circ}$ vs IO $28 / 30$ more than $10^{\circ}, p=0 \cdot 244$ ). It is possible that if only a small window is made in the IO membrane that the transfer would get adherent there. This may explain previous observations ${ }^{4,11}$ that the CT route provides a better ROM than the IO route. In this series the IO membrane was widely opened. There have been no vascular complications from this. The ROM of both groups in this study was similar (CT $\left.21 \cdot 3^{\circ}, \mathrm{IO} 18 \cdot 3^{\circ}, p=0 \cdot 374\right)$.

The $\mathrm{IO}$ route is associated with better active ADF though less active plantar flexion both at discharge and at final follow-up when compared with the CT route. This may reflect the attachment of the tendon at a higher tension. It also reflects the greater efficiency of the transferred force from the tendon acting at a better angle of pull in the IO route.

It is noteworthy that the ADF will drop by $10^{\circ}$ between the angle of suture and discharge from hospital. The ADF will drop a further $5^{\circ}-10^{\circ}$ between discharge and late follow-up (average fall- $\mathrm{CT} 8 \cdot 4^{\circ}$, IO $4 \cdot 3^{\circ}$ ). It is essential to suture the tendons with the foot dorsiflexed to at least $70^{\circ}$ to allow for later stretching of the muscle-tendon unit.

\section{Conclusion}

TPT is an excellent procedure for the correction of footdrop due to leprosy neuritis, resulting in a normal gait in $94 \%$ of patients. To avoid recurrent inversion the IO route is preferred. An open TAL should always be performed. The TP tendon should be attached to TAN and to PB or PT tendons wherever possible. It may be attached to toe extensors only if there are no toes or the toes are not mobile otherwise clawtoes may result. The tendons should be sutured with the foot dorsiflexed to at least $70^{\circ}$ as the foot will drop at least $10^{\circ}$ between removal of POP and follow-up at one year. Three weeks immobilization in a POP cast at $65^{\circ}$ to relieve tension on the anastomosis is sufficient, and is followed by 6 weeks graduated postoperative re-education. Full weight bearing and active plantar flexion are permitted at 6 weeks postoperation.

\section{References}

1 Andersen JG. Foot drop in Leprosy and its surgical correction. Act Orthop Scand, 1963; 33:2, $151-171$.

2 Andersen JG. Foot drop in leprosy. Lepr Rev, 1964; 35: 41.

${ }^{3}$ Carayon A, Bourrel P, Bourges M, Touze M. Dual transfer of the posterior tibial and flexor digitorum longus tendons for drop foot. J Bone Joint Surg [Am], 1967; 49A: 144.

4 Fritschi EP, Brand PW. The place of reconstructive surgery in the prevention of foot ulceration in leprosy. Int J Lepr, 1957; 25: 1-8.

5 Gunn DR, Molesworth BD. The use of tibialis posterior as a dorsiflexor. J Bone Joint Surg [Br], 1989; 39B: 674.

${ }^{6}$ Hall G. A review of drop-foot corrective surgery. Lepr Rev, 1977; 48: 185-192. 
7 Malaviya GN. Surgery of foot drop in leprosy by tibialis posterior transfer. Lepr in India, 1981; 53: 360-8.

8 Palani N, Selvapandian AJ. Pre- and post-operative physiotherapeutic management of foot-drop in leprosy. Lepr in India, 1969; 317-22.

9 Richard BM. Interosseous transfer of tibialis posterior for common peroneal nerve palsy. J Bone Joint Surg [Br], 1989; 71B: 834-7.

10 Schipper A, Lubbers WJ, Hogeweg M, de Soldenhoff R. Disabilities of hands, feet and eyes in newly diagnosed leprosy patients in eastern Nepal. Lepr Rev, 1994; 65: 239-247.

11 Selvapandian AJ, Brand PW. Transfer of the tibialis posterior in foot drop deformity. Indian J Surg, 1959; 21: 151 .

12 Srinivasan H, Mukher jee SM, Subramaniam RA. Two-tailed transfer of tibialis posterior for correction of drop-foot in leprosy. J Bone Joint Surg [ Br ], 1968; 50B: 623-28.

13 Thangaraj RH. Drop foot in leprosy and its treatment. Lepr in India, 1969; 314-6.

14 Warren AG. The correction of foot drop in leprosy. J Bone Joint Surg [Br], 1968; 50B: 629-34.

15 Weber MW,van Soest A, Neff G, Chiang T, Pfau R. Results of surgical procedures for the correction of foot-drop and of lagophthalmos due to leprosy. Lepr Rev, 1992; 63: 255-262.

16 van Braekel WH, Khawas IB. Nerve damage in leprosy: an epidemiological and clinical study of 396 patients in west Nepal-Part 1. Definitions, methods and frequencies. Lepr Rev, 1994; 65: 204-221. 